\title{
Media Control \& Manipulation and the concept of Responsibility to Protect: New Threats Posed to International Security
}

\author{
Wenbin $\mathrm{Wu}^{1}$, Shihao Wang ${ }^{2}$, Yandan Wang ${ }^{3}$, Tian $\mathrm{Xie}^{4}$, Yimeng Shen ${ }^{5}$ \\ ${ }^{1}$ Ruian Affiliated School, Beijing Foreign Studies University, Wenzhou, Zhejiang 325205, China, \\ real_WalterWu@163.com \\ ${ }^{2}$ Thurgood Marshall College, University of California, San Diego, La Jolla, California 92093, USA, \\ s6wang@ucsd.edu \\ ${ }^{3}$ The Experimental High School Attached to Beijing Normal University, Beijing 100069, China, selene826@163.com \\ ${ }^{4}$ COFCO 28 Degrees North Latitude, Changsha, Hunan 410129, China, uricaxt@ gmail.com \\ ${ }^{5}$ Handsworth Secondary, North Vancouver, British Columbia V7R4G2, Canada, lionmegnize824@ gmail.com
}

\begin{abstract}
To purpose of development and promotion of human welfare, a solid foundation of international security is essential. However, in the past history, the longed international security has been challenged by various threats in different forms and extents constantly; correspondingly and simultaneously, venerable predecessors in fields particularly of International Relationship keep focusing on the cause, influence, and solution of those threats.

To continue this unfinished work, a panoramic view to the cause influences and possible solution upon two threats--1) controversy in the concept of Responsibility to Protect 2) Pathetic media control and manipulation is presented in this essay; to the promotion of R2P framework, solutions is founded in the field of Science and Technology (S \& T).
\end{abstract}

Keywords: International security threats, Responsibility to Protect, Media control and manipulation, Science\&Technology.

\section{INTRODUCTION}

Since there was a state, there have been international security issues. International relations scholars have various definitions of "international security" and have discussed the nature of international security from different angles. However, no matter how "international security" is defined, it cannot be denied that the most fundamental connotation of national security is that the existence and development of a country is not threatened or infringed by external forces.

The rise of high and new technology has rapidly expanded the bounder of human production, and technology has increasingly become a significant part of productivity and the economy. At the same time, security issues in the international community have become increasingly prominent and given a broader content: traditionally concerned sovereign security, territorial security, political security, and military security; economic security, technological security, and cultural security that are becoming increasingly important in contemporary times; as well as information security and ecological security that have been valued in the information age.

Sovereignty security and territorial security are the core of the entire international security, and the abuse of R2P has highly affected this international security issue. At the same time, due to the fundamental decisive role of the economy in social and historical development, economic security is also the foundation and basic guarantee for the security of the entire country. With the increasing rate of science and technology's contribution to economic development, economic security inevitably includes the requirements for science and technology. Therefore, for the country, information security is a brand-new content of international security: the emerging threats of Media Control and Manipulation have become one of the issues that the international community should consider.

The misrepresentations of R2P, and media control and manipulation, as the two most serious new international security threats, should get people's attention and resolution. This essay suggests that people need to value the $S \& T$, as a double-edged sword that can both aggravate the media control and manipulation, and 
solve the misrepresentations of R2P. Since political efforts cannot solve R2P well independently, through the connection between these two threats, people can use technology in the cyber domain to solve the threats that $\mathrm{R} 2 \mathrm{P}$ brings to the international community.

\section{MEDIA CONTROL AND MANIPULATION}

We have come a long way in a cliché that best fits the advancements we have in modern society. Humanity has advanced over the years to create a peaceful and controlled environment around it. We have overcome most of the primary challenges we faced and have even furthered our agenda by exploring and exploiting our surroundings to meet our needs. One of the greatest innovations in modern society has been media and communication. These two aspects have formed a basis for data management, transfers, and socializing. The advent of social media changed the world by making it seem like a global village [1]. We can instantaneously interact with various people from across the globe with ease. However, this technology has come with some adverse effects on society. Current society has witnessed media control and manipulation cases at an unprecedented level, which has posed a threat to international security.

Media has a significant impact on our daily lives and has been one of the most influential systems in modern society. It has been known to change public perception and opinion on different significant topics in many nations. Many people have speculated that what the general public knows, thinks about, and regards as important is based on what the media has reinforced in them through the daily passing of the information [2]. Outside of personal experiences, the media informs people what line of thoughts they should perceive about specific topics or realities in the world. In governance, this immense power could be used as a tool by the government to sway citizens' decisions on particular policies. The media could be used by different forms of governments to control their people, even in aspects of democracy [3]. In recent times, many have realized that both authoritarian and democratic governments use media to shift the political mindset of people to stay away from politics.

Many people have noticed a changing pattern in governance that contradicts traditional aspects of the rule of law and public participation. A previous theory suggested that people had a free and fair opportunity, but that has changed in contemporary society [4]. In current society, many people have failed to participate in governance as traditionally expected. Many have suggested that different forms of government such as democratic and authoritarian governments coupled with influence from the media have been a significant factor in the issue. Both forms of government have realized the substantial influence possessed by different forms of media and have manipulated it to advance their agenda, especially in segregating power in governance. Democratic governments such as the USA and authoritarian governments such as North Korea have used media to discourage political competition, such as forming new parties or entering independent candidates into politics. In North Korea, the media has been used to show the harsh consequences of political competition with the ruling regime. Using this tactic, the government can discourage people from forming or running in any form of politics; thus, power is consolidated. In the USA, the government has used the influential power of media to show the public that politics is hard and tough. They also portray that politics is for influential and wealthy individuals; therefore, many people fail to join. In both these forms of government, the media is used to consolidate power to the governments.

The primary role of an opposition party is to ensure that the ruling party does not take any action to jeopardize the welfare of the people. They hold the government accountable for their actions to the public. They also offer constructive criticism, put restrictions, safeguard the people's liberty, help the government in some key projects, and express public opinion. These roles are all supported by the media in those nations. For the opposition parties in any state to fulfill their obligation, the media must convey the message to the public [5]. They can also use media access to the masses to learn the will of the people, which makes them more efficient in their tasks. Most opposition parties undertake these actions to portray themselves as a better and more efficient option than the government. They use the media's influence to gain support in attempts to gain a better foothold in the nations' politics. These actions, coupled with media influence in society, help convince the public they are more suited for governance.

Media is influential in all aspects of our lives, especially in terms of governance. What people are informed by media significantly influences their perception of particular topics. This has mainly been witnessed in politics, where different governments use this powerful tool to sway people's opinions and thought. In democratic nations, media is perceived as a critical pillar as it helps inform and pass down the power of the government to the people. People's perception of what the government or opposition parties do and how they operate is mainly passed through the media [6]. For this reason, some regimes have manipulated the media to portray the ideology of democracy while they are not. Such a case is in Russia, where the media portrays the opposition party as a strong and free party that checks the government's actions. Still, in practice, the party is controlled and does not have any authority in government operations. This shows how authoritarian governments can use media to portray democracy while, 
in practice, the government has consolidated all the power.

The advent of social media has significantly transformed modern society. The media helps people communicate, share and interact with people from across the globe. It has helped make the world a global village with people from all corners of the world and different aspects of social, political, religious, and economic levels getting a platform to interact. However, these benefits have come at a costly price to some level. The free access provided for all also applies to most radical groups in society. Al-Qaeda and its affiliates have also realized the access provided by social media, and they have also seized the opportunity [7]. They have developed strategies to manipulate the lonely and isolated youth and radicalized them to join their ranks. Cases of Americans being recruited over the internet have increased. The goal is achieved through media manipulation by terrorist groups. They target lonely, isolated people and give them purpose and a sense of belonging before they finally radicalize and recruit them. Social media has also provided these groups with the platform to publicize their ideologies to the world. Therefore, media control and manipulation have created a new frontier of war, creating an international security threat.

Another challenge caused by the advent of social media is that terrorists can use the platform to acquire and analyze data on different societies. Data collection has been made easier with billions of people joining social media platforms and sharing information on the platforms. Terrorists can use media to study and understand different aspects of society through these platforms [8]. They can communicate, target, and even cause harm through social platforms. They can also use misinformation to destabilize the target society. Therefore, media control and manipulation have created a new international threat.

All in all, advancement in technology has brought many benefits to modern society. One of the most important innovations has been the advent of different forms of media. However, technology has brought good things and some negative implications as well, which have caused an international security threat. The media has done this because it has been relied upon as one of the pillars of democracy. The media act as a watchdog and ensures that government leaders operate with the utmost integrity. However, media control by these governments may harm society as it will render them unable to make proper choices due to a lack of reliable information. In authoritarian governments, media is controlled and manipulated to keep the citizens unaware and unconscious of their freedoms and rights. The role of media has also impacted the objectives of opposition parties. These parties use the media to keep citizens informed of the government's actions. However, media manipulation of the government by the government could destabilize the operations of the opposition, while manipulation by the opposition party could have the same effect on the government. Terrorists have been found to use social media to recruit and radicalize youths. They also use the platform to voice their ideologies to the world. The advent of media has brought many advantages and has also brought a component of security threat to the world.

\section{CONTROVERSY IN THE CONCEPT OF RESPONSIBILITY TO PROTECT (R2P)}

The principle of $\mathrm{R} 2 \mathrm{P}$ refers to sovereignty entails a responsibility to protect all populations from mass atrocity crimes and human rights violations. Otherwise, International community will adopt diplomatic or military intervention to this country. $\mathrm{R} 2 \mathrm{P}$ is a principle used by the United Nations to protect countries from genocide, war crimes, ethnic cleaning and so for. It is served as a solution. In recent years, however, there have been some vague standards for implementing this principle. This gives some countries an opportunity to use it as a tool to infringe the national sovereignty of other countries.

\subsection{The existence problems of Responsibility to protect}

Due to the unlimited power R2P grants international roles over a certain region and population, it therefore causes ambiguity and uncertainty during the process of UNSC intervention that can be regarded as a great threat to the state's sovereignty and international security. These criteria are: 1) the severeness of the conflict in the region; 2) the motive or primary purpose of the proposed "humanitarian intervention"; 3) whether there is a reasonable and viable alternative to peace rather than military action; 4) the scope to which military action will respond; 5) whether the overall advantages of military incursions outweigh the disadvantages and assess its influence on the whole international security system.

Though Responsibility to Protect was established with well intention to prevent any crimes against humanity and address humanitarian violations worldwide, the ambiguous and impractical character of R2P that might jeopardize the stability of international security can be exemplified by the five criteria stated above. The most concerning defect of R2P is its uncertainty in assessing whether the humanitarian crisis in certain region meets the standard for NGOs to intervene and implement coercive military actions [8]. Besides, the problem of the consistency of R2P standard in dealing with every case poses difficulty in the process of conducting intervention.

To begin with, initially justifying extreme actions such as military operations require large-scale loss of life or ethnic cleansing. This criterion is used to determine whether the extent of the harm is sufficient to justify 
military action. This standard regulates the use of $\mathrm{r} 2 \mathrm{p}$ in a sense, but it does not work at all in the international community. In a sense, this standard state that if the severity of the harm caused is not sufficient to achieve a certain amount or influence, human military action will not be taken. At the same time, this criterion does not provide a clear range of damage levels. We don't know exactly how much damage is needed to justify military action. This offers an opportunity for some countries to take advantages of it.

Second of all, after justifying military action, the next criterion is the main motive for military action. This standard is primarily intended to deter or avoid the emergence of other purposes. Prevent some countries from using $r 2 p$ as a tool to violate others. However, we will prove in subsequent case studies that this standard does not work today. The reason is that, while we need to provide the purpose for which military action is taken, that does not mean that all States will honestly tell the Council the real reason. That's also one of the greatest problems of $\mathrm{r} 2 \mathrm{p}$ existed today and we'll demonstrate later: the unclear assessment of internal affairs meets the requirement of $\mathrm{r} 2 \mathrm{p}$.

Thirdly, having elaborated on the rationality and the main reasons, the criteria take into account whether there is an alternative to peace that would not allow such military action to take place. In our opinion, this is a complete waste of time. It's irrational and unnecessary to consider about whether there is a peace resolution after we corroborate the demand of humanitarian military action.

Fourth of all, relating to the scope to which military intervention can affect. In this criterion, we need to predict the general outcome of the military action which is full of uncertainty. The standard of the $\mathrm{r} 2 \mathrm{p}$ principle seeks to guarantee world peace with certain military operations, but greatly limits military operations.

Finally, it's about weighing the pros and cons. Weighing whether a military invasion has more advantages than disadvantages. I think this one seems to be the most reasonable of all the standards in this principle. We need to consider taking a military invasion before and after the world. This allows the $\mathrm{r} 2 \mathrm{p}$ principle to be used in the greatest sense.

Overall, the $\mathrm{r} 2 \mathrm{p}$ criteria is largely opposed to the second pillar of its three pillars. That is, timely and decisive action should be implement. Whereas it is impossible to take timely and decisive action by such cumbersome criterion. We cannot imagine what the modern impacts are going to have if these standards are brought to international society under the circumstance in which the actions are taken so untimely and indecisive.

Furthermore, R2P allows the international NGOs to dictate a foreign will over national governments, proposing a mechanism of protecting citizens derived from the very concept of national sovereignty. Avoidance of "humanitarian intervention" is to disperse the resistance of the idea that international role in addressing countries internal affairs.

\section{LINK BETWEEN MEDIA CONTROL \& R2P}

The question proposed clearly and unavoidable: In what way, can the international world address the existed dispute over the implementing boundary and its criteria upon the five issues presented above. To answer this question, a collective consensus have to be reached through political gaming. However, by observing the feature of political gaming: 1) time-required 2) undetermined and volatile, the international world have to accept the fact that such collective consensus is unquestionably a long and tough project; on the same time, numerous complex problem in the implement of $\mathrm{R} 2 \mathrm{P}$ is waiting for a proper solution in order to save millions of life from forms of atrocities. Therefore, a new approach for the enhancement of the R2P is urgently needed. Fortunately, the $S \& T$ developed in the past decades have open the door for the international world to enhance and strengthen the implement of R2P.

In following section, we will elucidate the difficulty of political movement in terms of R2P by presenting the two weakness of political gaming, and demonstrate how could Science and Technology ( $\mathrm{S} \& \mathrm{~T}$ ) enhance the implement of R2P specifically to three stage of R2P implementing.

\subsection{The two weakness of Political gaming}

The international world has dispute upon the criteria and boundary of the R2P, and the formal and conventional way to address this dispute to reach a collective consensus is through discussion and compromise among actors in the international world, which is essentially a process of political gaming. In follow, I will present the two weakness of Political gaming 1) time-required 2) undetermined and volatile, to discuss the difficulty for addressing the two major issue mentioned above through political gaming.

Political gaming is time-required, and may fail to reach ideal results in the end. In terms of a typical atrocity case happening in one region, member states and scholars in the international community have different voice on how to take their responsibility. To react effectively and in time, the international community have to reach a common ground or the huge loss in the conflict region is irremediable. With forceful intervention of bombing on Kosovo and Libya, NATO have addressed the regional atrocity in the end. However, this case of international humanitarian intervention proven to be highly controversial [9]. some scholars argue that, by forceful intervention, the $\mathrm{R} 2 \mathrm{P}$ has contributed to a new 
militarism which deviate the humanitarian nature of R2P; on the same time other scholars state that this is merely a military strategy of western world for the expansion and establishment of liberal democracy [10]. In the case of future atrocity, the dispute of response upon atrocity has to be compromised in time and take action collectively. The long and endless argument is harmful to a remedial action to take place in time, and results in a huge loss of life.

The results of Political gaming are undetermined and volatile. The attitude of international world is originally different and varied over time. Hold the humanitarian principle of the $\mathrm{R} 2 \mathrm{P}$, the international intervention must serve for the purpose of halt and avert the human suffering, once the feedback of supposed effective and proper intervention is deviate from the expectation. common ground reached before upon the implement of $\mathrm{R} 2 \mathrm{P}$ is collapsed, and following is the debate over a proper intervention and its specific conduct reopened. Furthermore, the actors, typically states is taking their own systemic interests into consideration regarding to the participation of international intervention under current framework of the R2P. Therefore, the opinion and action of them is temporary and unstable dependent on the current situation change in the international environment.

The basic unit of political gaming is unchangeably to be the state. It is undoable and irrational to ask any states in this world of mankind to lift the humanitarian sense over its systematic interests. Therefore, the political feature of time-required and volatile is improbable to be eliminated in a long run. In a word, if the political progress in the R2P framework is hard to be made, the international world should find any possible way to make progress in the $\mathrm{R} 2 \mathrm{P}$ framework while sticking to nature of R2P: humane.

\subsection{The enhancement of $R 2 P$ with Science and Technology $(S \& T)$}

With decades of development, the $\mathrm{S} \& \mathrm{~T}$ in the information age can have many positive impacts upon the implement of R2P. In the R2P implemental framework, the process can be divided into three stages 1) to prevent before atrocity2) to react during atrocity3) to rebuild after atrocity. In the follow, I will present how can the $\mathrm{S} \& \mathrm{~T}$ being utilized by the international community for the enhancement of R2P implement in terms of its three stages one by one.

\section{Stage One:}

Before, before the happen of atrocity. Subjected states, international community, and the UN member states take their responsibility of preventing the atrocity. The work done in the Stage one is prioritized due to the serious consequence of forceful intervention in the next two stages.
While the miniaturization allows the further and more sophisticated convergence of previous technologies, the worldwide popularization of cellphone and the increase availability of signals and data in remote and dangerous region, the local population can garner the evidence of misbehave and spread across regions and regions in the support of social media. Consequently, the "participatory peacekeeping" where the people in the occasion is able to help identify threats, criminal activity, and monitor cease fires or any aberrant behavior of protagonist, is created.

With digital verification procedure, potential conflict and its precondition can be recognized and recorded, helping determine and address the culpability, brutal practices, and corruption within a whole process of problem solving [11]. Further, the information and evidence collected creates strong imperative for urgent humanitarian intervention and encourage the results of political-gaming incline to a effective and determined humanitarian intervention rather than a veto of states end with no results. In a word, a systematic early warning system is finally constructed from warning to decisionmaking to react. Needless to say, many atrocities supposed to happen would be address in its early stage (Stage One) with millions of lives saved.

\section{Stage Two:}

During, during the atrocity. International community and the UN member states take the responsibility to react. The work done in the Stage two is to stop the ongoing atrocity by coercive powers in order to save lives.

Aerospace observation, by satellite or aircraft in cooperation with the real-time geographic information systems (GIS) pave way for observing and analyzing the situation on the ground [11].

Consequently, the UN response to changing situation can be deliver in time. The participation of unmanned aerial vehicles (UAV) in aerial reconnaissance have already save lives with its wide and accurate observative image, by sending message for UN rescue. Consequently, the potential cause of atrocity can be spotted and eliminate, which prevent the atrocity beforehand in the Stage Two.

The GPS tracking allow UN mission to follow their vehicle in a real time and accurate condition even in the dangerous and remote areas. This allows the Security Council to deploy the police, military, and civil peacekeepers precisely to conduct intelligence-led operations and modern operations [11]. Consequently, a new age of precise digital peacekeeping equipped with latest technology for positioning, tracking, sensing, and communication is coming. Such picture of effective react and response have been long demanding and craving. Increase the chance of successful intervention in the 
Stage Two can halt and avert the human suffering effectively and timely.

Stage Three:

After, after the atrocity. Subjected states, international community, and the UN member states take the responsibility to rebuild. The work done in the stage three is to help create the necessary national capacity for a sustainable peace.

With the invention and development of sophisticated technologies for the detection and removal of IED (improvised explosive device), the explosive remnants and mines can be clear effectively and safely [11]. Consequently, the chance of death and hurt in the Stage Three caused by millions of mine remained after armed conflict is significantly lowered.

Through the face pixilation and voice-modification technology, the visual and voice anonymity is given to the witnesses who may suffer the intimidation of perpetrators by telling truth, so the witness is encouraged to stand out and tell the truth. Consequently, a empowered court system is constructed in the transitional justice of the Stage three.

\subsection{More recommendation to the international world}

The modern science and technology $(\mathrm{S} \& \mathrm{~T})$ share a huge potential of enhance the R2P framework in term of its implement and conduct, yet the international world still stands on the start point of employ $S \& T$ to serve for the humanitarian causes in the R2P. An office of S \& T is demanded to contribute the constructive recommendation that $S \& T$ can help and achieve in the field of R2P, and deliver a comprehensive emergency response to any possible threats lead to the outbreaking atrocity.

For end, known the unchangeable feature of timerequired and volatile, the international world still has ways to deal with the rampant atrocities around world effectively under the framework of R2P. The S \& T open a door for in term of its three stage: preventing, reacting, and rebuilding, especially a systematic early warning system which handle potential atrocity well in its early stage. However, the political progress in the R2P is so important and urgent to be made. Compromise and concession are the cure required in whatever kind of political gaming. It is time for the international world to take the cure regarding to the $\mathrm{R} 2 \mathrm{P}$, and the lift the humanitarian value higher in the bargaining table.

\section{CONCLUSION}

The advent and development of technology have changed the world with some adverse effects. Although the technology itself is a threat to international security, as a double-edged sword, good use can help the international community solve the security threats brought by $\mathrm{R} 2 \mathrm{P}$.

Specifically, technology has immense power to sway citizens' decisions by the government and radical groups in society such as terrorists. The media bears a great social responsibility, which is related to social stability and order as well as the guidance of public opinion. As media is used to disseminate information and act as a supervisor, it imperceptibly guides the public's way of thinking and foci on problems because people trust in public media. However, when the media is used and guided by malicious groups, the media can cause great trauma to citizens' lives. On the government side, both authoritarian and democratic governments use media to control people and shift the political mindset of people by creating a false image of the government. To radical groups, developed strategies from the data manipulate the lonely and isolated youth and give them purpose and a sense of belonging to recruit them. Young people are easily influenced by the information in the media and believe in what they see and think so that they make irrational speeches and actions under the influence of the group polarization effect.

Another international security threat besides media control and manipulation is $\mathrm{R} 2 \mathrm{P}$. R2P originally is a principle composed to protect citizens of another country, which means when a country is unable or unwilling to take the responsibility to protect its citizens, the international community has the responsibility to take collective action to provide protection. If there is neither an international system nor a balance of power system, this kind of "right to conviction" is at risk of being abused. With this principle, sovereignty no longer fully protects countries from external interference. Therefore, all this must be carried out under strict criteria. Currently, the criteria still have problems to be solved. This criterion does not provide a clear range of its request so that allows other countries to take advantage of R2P. Besides, the cumbersome standards and procedures prevent other countries from taking decisive actions promptly.

As problems in $\mathrm{R} 2 \mathrm{P}$ implementation are waiting for appropriate solutions, Science and Technology (S\&T) can standardize the implementation of R2P. Since R2P is Highly controversial in its criteria and boundary, people must reach a collective consensus through political gaming. The problems are unchangeable that it takes a long time for people to reach a consensus and take action when facing atrocities and that the opinion and action of countries are temporary and unstable. Therefore, the S\&T can be utilized for the enhancement of R2P implementation in terms of its three stages, preventing, reacting, and rebuilding. Before the atrocity, with the support of social media, the local population can garner evidence of misbehaving which encourages the results of political-gaming incline to an effective and determined 
humanitarian intervention. Besides, potential conflict and its precondition can be recognized and recorded to better identify threats. During the atrocity, S\&T able countries to respond to changing situations promptly by satellite, aircraft, and GPS tracking. After the atrocity, explosives and mines can be removed effectively and safely with technologies for the detection and removal of IED. Through face pixelation and voice-modification technology, the safety and interests of witnesses are guaranteed, which standardizes the court system. Using S\&T, the threat of R2P can be well resolved.

Reflection on war and peace should become the theme of the times. Although peace itself is far away, the international community will never give up its efforts to seek peace.

\section{REFERENCES}

[1] Mayfield, T. (2011). A Commander's Strategy for Social Media. Ndupress. Ndu. Edu, 1(60), 81. Retrieved April 28, 2021.

[2] Fields, B. Impact on Public Perceptions, Educational Decisions and Policy. University Of Southern Queensland. Retrieved 2 May 2021, from https://core.ac.uk/download/pdf/11039769.pdf.

[3] Parvin, P. (2017). Democracy Without Participation: A New Politics for a Disengaged Era. Springer Link. Retrieved 2 May 2021, from

[4] Baum, Matthew A., and Philip B.K. Potter. " The Relationships Between Mass Media, Public Opinion, And Foreign Policy: Toward A Theoretical Synthesis".

[5] Marwick, Alice, and Rebecca Lewis. " Media Manipulation And Disinformation Online." Data \& Society, Retreived April 28, 2021.from http://datasociety.net.

[6] Thompson, R. (2011). Radicalization and the Use of Social Media. Journal Of Strategic Security, 4(4), 168. Retrieved 28 April 2021, from https://www.jstor.org/stable/26463917?seq=1\#met adata_info_tab_contents.

[7]. Mayfield, T. (2011). A Commander's Strategy for Social Media. Ndupress.Ndu.Edu, 1(60), 81. Retrieved April 28, 2021.

[8] Robert A. Pape. "When Duty Calls: A Pragmatic Standard of Humanitarian Intervention" International Security (2012) 37 (1): 41-80.

[9] Bassiouni, C. (2009). Advancing the Responsibility to Protect Through International Criminal Justice. Responsibility to Protect, 31-42. doi: 10.1057/9780230618404_3
[10] Hehir, A., \& Murray, R. W. (2013). Libya, the responsibility to protect and the future of humanitarian intervention. New York (NY): Palgrave

Macmillan.https://link.springer.com/article/10.100 7/s11158-017-9382-1.

[11] Dorn, Walter \& Lloyd Axworthy (2016). "New Technology for Peace \& Protection: Expanding the R2P Toolbox." The MIT Press, 2016. www.jstor.org/stable/24916786. 